\title{
Role of lysosomes in cancer therapy
}

\author{
This article was published in the following Dove Press journal: \\ Research and Reports in Biology \\ 28 September 2015 \\ Number of times this article has been viewed
}

\section{Reginald Halaby}

Department of Biology, Montclair State University, Montclair, NJ, USA

Correspondence: Reginald Halaby

Department of Biology, Montclair State University, I Normal Avenue,

Montclair, NJ 07043, USA

Tel +l 9736557982

Email halabyr@montclair.edu
Abstract: Lysosomes are acidic organelles that are involved in cellular digestion by endocytosis, phagocytosis, and autophagy. They contain more than 50 hydrolases that are capable of degrading all macromolecules. There is accumulating evidence that lysosomal enzymes can provoke apoptotic cell death. This has important implications for cancer, where proapoptotic genes are mutated and antiapoptotic genes are often overexpressed leading to chemoresistance. Lysosomes play a dual role in cancer development depending on their subcellular localization. When they are located extracellularly they can promote invasion, angiogenesis, and metastasis. However, when they are located intracellularly they can trigger apoptosis by leaking into the cytosol. In this review, we examine the pathways by which lysosomes can evoke both apoptosis and tumorigenesis. Although cancer cells have defects in their apoptotic machinery, they can still undergo lysosomal cell death. We offer several strategies to explain how targeting lysosomes can serve as a putative model for the development of novel anticancer agents. Furthermore, we propose that lysosomal cell death is an effective treatment against apoptosis-resistant cancer cells and thus holds great potential as a therapeutic strategy for circumventing apoptosis deficiency in tumors.

Keywords: cathepsins, lysosomal membrane permeability, apoptosis, chemoresistance

\section{Introduction}

Lysosomes, discovered more than 50 years ago, are the major cell-digestive organelles that degrade extracellular materials taken up by the cell and intracellular components under certain conditions. ${ }^{1,2}$ They contain a number of hydrolases that are capable of breaking down nucleic acids, proteins, carbohydrates, and lipids. However, it is becoming more evident that these organelles function more in the cellular digestion process. It has taken some time to recognize that lysosomal proteases play a role in programmed cell death (PCD) for the following reasons. Some inhibitors that were used to evaluate the role of caspases in PCD also inhibit several cathepsins that function as effectors of lysosomal cell death. ${ }^{3,4}$ Furthermore, lysosomal involvement in PCD has been overlooked because the morphology of the lysosomal membrane often appears intact even after proteases have translocated into the cytosol. ${ }^{5}$ Today, it is clear that lysosomes and lysosomal proteases are involved in apoptosis. Lysosomal cell death or type II cell death ${ }^{6}$ is characterized by early lysosomal destruction of the cytoplasm with nuclear degradation being a late event. In type II cell death, a ladder of fragmented DNA may be generated, but only after much of the cytoplasm has already been destroyed. ${ }^{7}$ Nuclear changes are often delayed and the cytosol is consumed by autophagic vacuoles in lysosomal cell death. ${ }^{7,8}$ Type II death is exemplified during 
normal development by the regression of the tadpole tail, ${ }^{9}$ involuting mammary gland, ${ }^{10}$ involuting prostate, ${ }^{11}$ and dying insect tissues. ${ }^{7,12,13}$ One of the first reports that demonstrated that lysosomotropic agents destabilized the lysosomal membrane triggering apoptosis was conducted by Li et al. ${ }^{14}$ Subsequently, several other studies have reported that agents that directly disrupt the lysosomal membrane confirmed that lysosomal membrane permeabilization (LMP) can trigger apoptosis and apoptosis-like cell death. ${ }^{15-17}$

\section{Lysosomes}

Lysosomes are the organelles that are responsible for cellular digestion, which were identified by Appelmans et al ${ }^{18}$ and de Duve et al. ${ }^{19}$ Figure 1 summarizes the various functions carried out by lysosomes in normal and cancer cells. Lysosomes perform cellular degradation by utilizing more than 50 hydrolases, including proteases, glycosidases, lipases, and nucleases. ${ }^{20}$ As a result of this wide range of enzymes, lysosomes can degrade all types of macromolecules. The hydrolases are active under acidic $\mathrm{pH}$, which is maintained by the action of the vacuolar $\mathrm{H}^{+}$-ATPase. ${ }^{21}$ The lysosomes are also involved in endocytosis, ${ }^{22}$ exocytosis, ${ }^{23}$ cholesterol homeostasis, ${ }^{24}$ chaperone-mediated autophagy, ${ }^{25}$ and macroautophagy. ${ }^{26}$ Figure 1 also demonstrates the dual role played by lysosomes in cancer cells. Lysosomal proteases that are secreted extracellularly can promote tumorigenesis. ${ }^{27-29}$ Overexpression of lysosomal proteases often correlates with poor prognosis and increased recurrence in many cancers. ${ }^{30,31}$ By contrast, cytosolic release of lysosomal enzymes has been demonstrated to trigger apoptosis and cell death. ${ }^{3,15,32}$
Mounting evidence indicate that lysosomal enzymes are good target molecules for cancer therapy. ${ }^{29,33,34}$

\section{Lysosomes in cancer cells}

Cancer cells have relatively large lysosomes ${ }^{35}$ and these are thought to be more fragile than normal-sized lysosomes. ${ }^{36}$ Moreover, cancer cells exhibit higher metabolic rates and an increased turnover of iron-containing proteins, leading to the lysosomal accumulation of iron, with consequent iron-mediated sensitization to reactive oxygen species (ROS)-induced LMP. ${ }^{37}$ Cancer cells often produce elevated ROS levels and the associated higher rate of spontaneous cathepsin release from lysosomes may facilitate cell death induction. ${ }^{38}$ On theoretical grounds, all of these factors render lysosomes from cancer cells particularly susceptible to the therapeutic induction of lysosomal-mediated cell death. Further studies are needed to confirm these observations. The presence of lysosomal-mediated cell death provides a uniquely useful option to treat tumor cells that are resistant to canonical apoptotic cell death. We propose that cancer cells are inherently more susceptible to lysosomal-mediated cell death than normal cells and that this very characteristic should be fully explored to design more effective antitumor agents. Furthermore, the enhancement of lysosomal cell death may be a therapeutic strategy to overcome inhibition to caspase-dependent cell death.

In contrast, cancer cells try to evade cell death by making modifications that affect their lysosomes. The increased activity of phosphatidylinositol-3-kinase (PI3K), which is characteristic of many tumors, may contribute to the

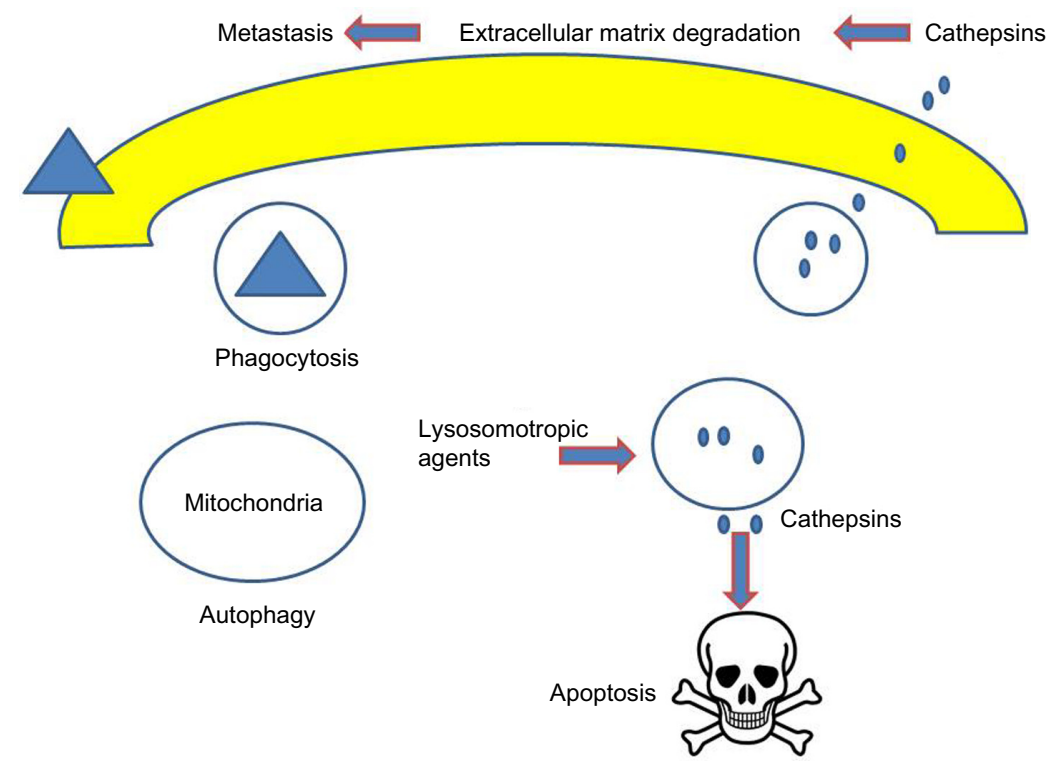

Figure I Various functions of lysosomes in normal and cancer cells. 
stability of tumor cell lysosomes. ${ }^{33}$ PI3K regulates several cell processes, including maturation, size, and activity of lysosomes, ${ }^{39}$ and the inhibition of PI3K can shift the TNF-induced cell death pathway from caspase dependent to cathepsin dependent. ${ }^{40}$ Cancer cells have developed mechanisms to inhibit LMP by overexpression of lysosomal cytosolic protease inhibitors. ${ }^{41,42}$ Furthermore, cancer cells translocate cytosolic Hsp70 to the lysosomal lumen where it stabilizes the lysosomal membranes by promoting the activity of acid sphingomyelinase. ${ }^{43,44}$ Tumor cells appear to protect themselves against cytosolic leakage of lysosomal proteases by translocation of Hsp70 into the lysosomal membrane. ${ }^{44}$ Depletion of Hsp70 triggers a tumor-cell-specific lysosomal cell death program. ${ }^{38}$ Finally, cathepsin inhibitors may increase the viability of cancer cells with enhanced lysosomal activity. ${ }^{45,46}$ Therefore, it is conceivable that drugs that inhibit the activity of PI3K, the lysosomal accumulation of Hsp 70, or the activity of cathepsin inhibitors may make tumor cells susceptible to lysosomal cell death.

\section{Lysosomes and cancer progression}

In addition to the role of lysosomal enzymes in triggering LMP, translocation of enzymes from the lumen of lysosomes to the cytosol, and triggering mitochondrial-mediated apoptosis, they have been documented to promote tumorigenesis. Cathepsins have been documented to promote tumors as well as acting as tumor suppressors depending on whether they are released intracellularly where they induce apoptosis or released into the extracellular matrix (ECM) where they stimulate metastasis. ${ }^{32}$ Malignant cells display increased proteolytic activity, which helps them to digest the ECM. Cathepsins have been shown to degrade the ECM components, such as elastin, laminin, and fibronectin, which facilitate invasion, angiogenesis, and metastasis. ${ }^{47-49}$ Upregulation of cysteine cathepsin protein levels has been detected in mouse and human cancers. ${ }^{49,50}$ Furthermore, there is a correlation between the expression levels of these proteins and clinical outcome. ${ }^{49,51-53}$ In some instances, lysosomal proteases are translocated to the plasma membrane and then secreted into the ECM. ${ }^{54,55}$ Using null mutants for cysteine cathepsin genes, it has been demonstrated that these genes contribute to pancreatic islet tumorigenesis. ${ }^{56}$ The exact mechanisms by which cathepsins promote their pro-tumor effects have yet to be fully elucidated.

Increased lysosomal enzymatic activity and secretion of the hydrolases into the extracellular space promotes tumor growth and migration, angiogenesis, and metastasis. ${ }^{27,57,58}$ Several members of the cathepsin family of proteases have been implicated in tumor progression. In particular, protein expression levels of cathepsins B, D, and L have been shown to increase. ${ }^{59}$ There is often a redistribution of lysosomes from perinuclear to peripheral locations in cancer cells and the lysosomal contents have been localized to the extracellular space. ${ }^{60}$ There are data supporting the premise that secreted cathepsins, working in collaboration with matrix metalloproteases and the plasminogen activator system, can degrade the ECM, thereby promoting cellular motility, invasion, and angiogenesis..$^{50,61}$

\section{Lysosomes and cell death in cancer}

The role of cathepsins in apoptosis is well documented. ${ }^{2,62,63}$ Cathepsins have been implicated as TNF- $\alpha$-induced apoptosis of murine fibrosarcoma WEHI-S cells ${ }^{3}$ and ovarian cancer OV-90 cells. ${ }^{64}$ Lysosomal cathepsins B and D modulate apoptosis involving cytotoxic drugs. ${ }^{65,66}$ One report showed that selective alteration of the lysosomal membrane with L-leucyl-L-leucine methyl ester resulted in apoptosis in HeLa cells that was characterized by translocation of cathepsins into the cytosol and cleavage of Bid. ${ }^{16}$ Lysosomes contain an activity capable of cleaving Bid. ${ }^{67,68}$ However, lysosomal hydrolases can trigger the intrinsic apoptotic pathway independent of Bid cleavage. ${ }^{15}$ LMP has been proposed as the primary mechanism responsible for the release of lysosomal proteases into the cytosol. ${ }^{63,69}$ Once released into the cytosol, cysteine cathepsins can induce liberation of cytochrome $\mathrm{c}$ from the mitochondria and subsequent activation of caspases. ${ }^{67}$ Lysosomal proteases migrate from the lysosomal lumen to the cytosol in response to various apoptotic stimuli such as TNF, ${ }^{3}$ Fas, ${ }^{70}$ p53 activation, ${ }^{71}$ microtubule-stabilizing agents, ${ }^{65}$ oxidative stress, ${ }^{72}$ and lysosomotropic agents. ${ }^{15}$

The exact mechanisms by which LMP modulates apoptosis are not well understood. It has been proposed that caspase- 8 is involved in the release of apoptotic factors from lysosomes. ${ }^{16}$ Another report demonstrated that triptolide sensitizes TRAIL-resistant pancreatic cancer cells to apoptosis by inducing LMP. ${ }^{73}$ Translocation of cathepsins into the cytosol occurs as a result of LMP. Lysosomal-mediated cell death serves as an important alternative death pathway for tumors that acquire chemoresistance via mutations in proapoptotic genes, such as executioner caspases, or antiapoptotic genes, such as XIAP and Bcl-2.

\section{Mechanisms of LMP}

There are several terms that are currently used to describe the process that results in the translocation of lysosomal 
proteases from the lysosomal lumen to the cytosol: lysosomal membrane destabilization, lysosomal membrane disruption, and LMP. There is some confusion as to how to accurately detect lysosomal membrane alterations and when to use these terms. It is generally accepted that they all involve damage to the lysosomal membrane. To further propagate the confusion, the structure of the lysosomal membrane can appear to be intact even after lysosomal proteases have leaked into the cytosol. ${ }^{5}$ Lysosomal membrane destabilization has been observed in hydrogen-peroxide-treated cells that displayed deformed and swollen lysosomes. ${ }^{74}$ Another study demonstrated lysosomal membrane destabilization in neuronal cells by detecting a loss in lysosomal proton gradient integrity. ${ }^{75}$ However, several agents have been shown to directly disrupt the integrity of the lysosomal membrane. ${ }^{16,17,72,76} \mathrm{~A}$ quantitative relationship between the amount of damage to the lysosomal membrane and the mode of cell death may explain the different morphological outcomes following LMP. Limited release of lysosomal proteases into the cytosol results in apoptosislike cell death, while massive rupture of the lysosomal membrane leads to necrosis. ${ }^{17,72}$ However, the exact mechanisms that regulate the translocation of lysosomal proteases into the cytosol remain unknown, and further studies are required to achieve a better understanding of this process.

The precise mechanisms responsible for lysosomal rupture are not yet completely understood. It is not known whether pores form in the lysosomal membrane or whether certain channels are involved in the relocation of lysosomal proteases from the lysosomal lumen to the cytosol. However, one can propose several plausible explanations. The presence of lysosomotropic agents, such as sphingosine, could accumulate in lysosomes, permeabilize lysosomal membranes, and facilitate the leakage of some lysosomal proteases. ${ }^{17}$ Downregulation of Hsp70 has been demonstrated to result in lysosomal destabilization, release of lysosomal hydrolases into the cytosol, and a caspase-independent cell death. ${ }^{44}$ Another possible explanation for provoking lysosomal rupture involves the production of ROS. Specifically, several stimuli that induce lysosomal leakage, such as TNF- $\alpha,{ }^{77}$ also generate the production of $\mathrm{H}_{2} \mathrm{O}_{2}$ during apoptosis. ${ }^{78,79}$ An alternate possibility is that proapoptotic proteins, such as Bax, may translocate into the lysosomal membrane and trigger lysosomal rupture. ${ }^{80}$ Photodynamic therapy has also been reported to induce lysosomal disruption, resulting in mitochondria-mediated cell death. ${ }^{81}$

Following their release into the cytosol, cathepsins cleave Bid and degrade antiapoptotic Bcl-2 proteins, thereby triggering the mitochondrial pathway of apoptosis, with LMP being the critical step in this pathway. ${ }^{63,82}$ Regardless of the trigger of LMP, it is generally accepted that cytosolic release of cathepsins precedes mitochondrial-membrane potential changes. ${ }^{17,68,83}$ How LMP is modulated by the complex Bcl-2 protein network, however, is still unclear. Various insults, including oxidative stress and DNA damage, may lead to the limited release of cathepsins that culminate in the induction of apoptosis. ${ }^{84}{ }^{87} \mathrm{Hsp} 70$ plays an important role in inhibiting LMP to promote the survival of stressed cells..$^{43}$ However, blocking cathepsins by small-molecule inhibitors has been shown to significantly delay cancer progression in a number of mouse cancer models as well as to sensitize tumor cells to other chemotherapeutic agents. ${ }^{88}$ The promoter region of cathepsin D contains two p53-binding sites and the authors concluded that cells that completely lack this protease exhibited increased chemoresistance. ${ }^{89}$ Lysosomal-mediated apoptosis is still largely under investigation and not fully understood.

\section{Targeting lysosomes in anticancer therapy \\ Lysosomotropic agents}

Drugs that are weak bases can accumulate in acidic organelles, such as lysosomes by an interaction described as the acidic shift. ${ }^{90}$ The accumulation of these basic drugs in lysosomes, which occurs because of the $\mathrm{pH}$ gradient across the lysosomal membrane and ion trapping, can result in cytosolic leakage of lysosomal hydrolases and cell death. ${ }^{91,92}$ To this end, Firestone et al designed a class of agents termed lysosomotropic detergents to treat cancer cells. ${ }^{93}$ This was demonstrated by showing that lysosomal entrapment of the imidazoacridinone C1311 resulted in lysosomal swelling and rupture followed by subsequent cytosolic release of proteases and cell death of HT-29 colon cancer cells. ${ }^{94}$ The use of lysosomotropic compounds as anticancer agents has increased. Lysosomes and lysosomal enzymes have also been postulated to play a role in the shrinkage of solid tumors. ${ }^{95,96,97}$ Furthermore, it has been described that the efficacy of radiation ${ }^{96}$ and hyperthermia ${ }^{97}$ are due, in part, to lysosomal enzymatic degradation and cytosolic leakage of these proteases. Mefloquine, an antimalarial agent, has been shown to possess antileukemic activity ${ }^{98}$ In this study, the authors demonstrated that the size of lysosomes were increased in acute myeloid leukemia cells and that mefloquine was toxic to acute myeloid leukemia cells while sparing normal hematopoietic cells treated with the same doses. ${ }^{98}$

The majority of chemotherapeutic drugs induce cell death via the mitochondrial-mediated intrinsic apoptotic pathway. Accumulating data indicate that cathepsins are located upstream of mitochondrial outer membrane permeabilization in this signaling pathway and can provoke mitochondrial 
outer membrane permeabilization. ${ }^{66,99}$ It was reported that a cathepsin B inhibitor reduced cell death and cytochrome c release in embelin (an inhibitor of XIAP)-treated colon cancer cells. ${ }^{100}$ This finding indicates that the lysosomal cell death pathway is upstream of mitochondrial death signaling. Other studies have demonstrated that lysosomal-mediated cell death in cancer cells can be caspase-independent. Resveratrol has been shown to activate apoptosis by promoting lysosome leakage and cytosolic translocation of cathepsin D in colorectal cancer cells. ${ }^{101}$ We have previously demonstrated that the Chinese herb triptolide, the bioactive component of Tripterygium wilfordii Hook $\mathrm{f}$, induces upregulation of the mature, active form of cathepsin B protein levels in cytosolic fractions of MCF-7 cells. ${ }^{102}$ Using LysoTracker Green, we detected an aggregation of lysosomes in experimental cells, but not in control cells. ${ }^{102}$ This lends support to the notion that LMP and cytosolic leakage of lysosomal proteases are upstream of mitochondrial changes in the intrinsic apoptotic pathway. ${ }^{32,103}$ Furthermore, when MCF-7 cells were stained with acridine orange, a fluorescent dye that accumulates in acidic organelles, control cells displayed distinct red fluorescence (lysosomal) while triptolide-treated cells displayed reduced red fluorescence and maximal green fluorescence (cytosolic). ${ }^{102}$ We were the first to report that the anticarcinogenic effects of triptolide were mediated via a lysosomal mechanism. ${ }^{102}$ This shift in fluorescence indicates that lysosomal membrane rupture occurred. Hsp70, a potent survival protein whose depletion results in caspase-independent apoptosis, has been shown to protect several cancer cells against death stimuli by inhibiting LMP. ${ }^{44}$ Another report showed that clioquinol, a metal chelator, targets zinc to lysosomes causing LMP, release of cathepsins, and apoptosis. ${ }^{104}$ Several reports indicate that anticancer agents that target lysosomes and induce lysosomal membrane disruption play a role in the fight against cancer. For example, chloroquine, a lysosomotropic drug, may prove to be such an agent and it has been reported to inhibit cell growth and induce cell death in lung cancer cells, ${ }^{105}$ myc-induced model of lymphoma, ${ }^{106}$ and has been used in clinical trials as adjuvant therapy for patients with glioblastoma multiforme. ${ }^{107}$ However, the antitumor effects of chloroquine are primarily based on its ability to inhibit autophagy. ${ }^{108-110}$ A recent study described how a novel agent, ARN5187, which has similar inhibitory properties on autophagy as chloroquine, is more cytotoxic to breast cancer cells compared to chloroquine treatment. ${ }^{111}$ Several agents that trigger LMP are currently utilized because of their antitumor effects (Table 1). This table is not meant to be an inclusive list of all the currently used lysosomotropic agents and cathepsin inhibitors.

It has been reported that the parvovirus $\mathrm{H} 1$ induces a nonapoptotic cell death in glioma cells that is mediated by the release of cathepsins in response to LMP. ${ }^{112}$ Exposure of immortalized and transformed cells to siramesine, a sigma-2 receptor agonist, in vitro has been demonstrated to result in extensive cell death. ${ }^{15,113-116}$ One study screened a drug library and identified 175 compounds that induced death in cultured colon cancer cells. ${ }^{117}$ Importantly, over half of the eleven compounds that induced significant cell death in p53-deficient cells triggered LMP and cathepsin-mediated killing of tumor cells. ${ }^{117}$ There is definitely a dire need for targeted anticancer therapies. To this end, a recent report employed a fluorescent small organic molecule, 3,6-bis(1methyl-4-vinylpyridinium) carbazole diiodide (BMVC), that selectively labeled the nuclei of cancer cells, but not normal cells. ${ }^{118}$ The authors of this study demonstrated that BMVC was retained in the lysosomes and was excluded from the nuclei of normal cells, which could explain the

Table I Various lysosomotropic agents and specific lysosomal protease inhibitors that possess anticancer properties

\begin{tabular}{|c|c|c|c|}
\hline Treatment & Cell type & Protein(s) & Reference \\
\hline Leelamine & Melanoma & RTK-AKT/STAT/MAPK & 124 \\
\hline BMVC & MCF-7, foreskin, and lung fibroblasts & Unknown & 118 \\
\hline Geldanamycin & HTB-26, MDA-MB-23I, HEK 293T, HL-60, fibroblasts & Hsp90 & 125 \\
\hline EGCG & HepG2, mouse embryonic fibroblasts & Unknown & 126 \\
\hline Triptolide & MCF-7 & Cathepsin B & 102 \\
\hline Chloroquine & MEF, PC3, U87MG & PI3K-Akt & 127 \\
\hline D-e-MAPP & MCF-7 & Unknown & 128 \\
\hline Symadex $(\mathrm{CI} 3 \mathrm{II})$ & HT-29 & Acid phosphatase & 94 \\
\hline Z-Phe-Gly-NHO-Bz & BT-20, PC3, U373, SQ20B, HELA, DU I45 & Cysteine cathepsins & 129 \\
\hline$\alpha$-ketoamide & A2058 & Cathepsin S & 130 \\
\hline JMV4463 & MDA-MB-23I, MCF-7, LNCaP, SaOs2, HCT-II 6 & Cathepsin D & 131 \\
\hline BPC & $\mathrm{K} 562$ & Cathepsin B & 92 \\
\hline CLIK-I48 & LJC-I, A375, 26 PMF-I5 & Cathepsin L & 132 \\
\hline Kalpaamruthaa & DMBA mammary gland xenograft & Cathepsin D & 133 \\
\hline
\end{tabular}

Abbreviation: BMVC, 3,6-bis(I-methyl-4-vinylpyridinium) carbazole; EGCG, Epigallocatechin Gallate; BPC, Biphosphinic Palladacycle Complex. 
observed selective hyperfluorescence of BMVC in cancer cell nuclei. ${ }^{118}$ These findings are very promising and suggest that it may be possible in the future to exploit differences in subcellular localization for cancer targeting for treatment modalities. Support for this theory is found in the fact that normal cells have acidic lysosomes with a $\mathrm{pH}$ range of $4-5$, whereas the cytosol is primarily neutral. ${ }^{119}$ Consequently, weak bases will accumulate in acidic organelles such as lysosomes. Several cancer cells have defects in lysosomal acidification. ${ }^{120-122}$ For instance, the lysosomal $\mathrm{pH}$ of HL-60 cells is 6.5 , however the cytosolic $\mathrm{pH}$ of these cells is neutral. ${ }^{123}$

\section{Cathepsin inhibitors}

Several recent reports have employed an antibody, an antibiotic, and a small molecule as potential therapeutic strategies for the treatment of tumors by specifically inhibiting the activities of various cathepsins ${ }^{94,124-126}$ (several of these agents are summarized in Table 1). In one study, the antitumor activity of Fsn0503h, the first human monoclonal antibody developed against extracellular cathepsin S, was examined. ${ }^{127}$ In that study the authors demonstrated that Fsn0503h does not affect the intracellular activity of cathepsin $\mathrm{S}$ and has in vivo antitumor activity in a Colo-205 mouse xenograft model. ${ }^{127}$ Nitroxoline is an antibiotic that possesses antiangiogenic activity. ${ }^{128} \mathrm{~A}$ recent report has shown that nitroxoline inhibited tumor growth, angiogenesis, and metastasis in vivo in breast cancer and fibrosarcoma models. ${ }^{129} \mathrm{~L}-235$ is a cathepsin K inhibitor that has been reported to reduce skeletal breast cancer tumor burden and breast cancer local metastasis in a xenograft model. ${ }^{130}$

\section{Conclusion}

With the development of novel, specific fluorescent probes for staining lysosomes ${ }^{131}$ in vivo, such as Superior LysoProbes, we should be able to have a better understanding on the exact mechanisms that regulate lysosomal membrane destabilization. Cell lines, such as MCF-7, which lack the apoptosis executioner protein caspase- $3^{132}$ and can undergo lysosomal-mediated cell death, ${ }^{102}$ should prove useful in deciphering the role of lysosomes as novel pharmacologic targets in human tumors. The utilization of anticancer agents that stimulate apoptosis via LMP and/or that effectively inhibit the extracellular tumorpromoting activities of cathepsins, should further support the hypothesis that targeting lysosomes is an effective form of cancer treatment. These data suggest that lysosomotropic drugs and specific lysosomal protease inhibitors may prove useful in the treatment of otherwise therapy-resistant human cancers and further research is warranted to identify such agents. Tumor cells exhibit specific alterations in their lysosomes: increased cathepsin enzymatic activity, modified lysosomal trafficking, and shifts in different endolysosomal populations. ${ }^{33}$ We propose that these differences in the lysosomes of cancer cells compared to normal cells can be exploited to sensitize tumors to cell death. The importance of lysosomal-mediated cell death has been underappreciated, yet holds great promise in the fight against chemoresistance because it provides an alternative pathway to kill cancer cells.

\section{Disclosure}

The author reports no conflicts of interest in this work.

\section{References}

1. de Duve C. The lysosome turns fifty. Nat Cell Biol. 2005;7(9): $847-849$.

2. Luzio JP, Pryor PR, Bright NA. Lysosomes: fusion and function. Nat Rev Mol Cell Biol. 2007;8(8):622-632.

3. Foghsgaard L, Wissing D, Mauch D, et al. Cathepsin B acts as a dominant execution protease in tumor cell apoptosis induced by tumor necrosis factor. J Cell Biol. 2001;153(5):999-1010.

4. Schotte P, Declercq W, Van Huffel S, Vandenabeele P, Beyaert R. Non-specific effects of methyl ketone peptide inhibitors of caspases. FEBS Lett. 1999;442(1):117-121.

5. Brunk UT, Neuzil J, Eaton JW. Lysosomal involvement in apoptosis. Redox Rep. 2001;6(2):91-97.

6. Schweichel JU, Merker HJ. The morphology of various types of cell death in prenatal tissues. Teratology. 1973;7(3):253-266.

7. Zakeri ZF, Quaglino D, Latham T, Lockshin RA. Delayed internucleosomal DNA fragmentation in programmed cell death. FASEB J. 1993;7(5):470-478.

8. Halaby R, Zakeri Z, Lockshin RA. Metabolic events during programmed cell death in insect labial glands. Biochem Cell Biol. 1994; 72(11-12):597-601.

9. Weber R. Induced metamorphosis in isolated tails of Xenopus larvae. Experientia. 1962;18:84-85.

10. Brandes D, Sloan KW, Anton E, Bloedorn F. The effect of x-irradiation on the lysosomes of mouse mammary gland carcinomas. Cancer Res. 1967;27(4):731-746.

11. Sandford NL, Searle JW, Kerr JF. Successive waves of apoptosis in the rat prostate after repeated withdrawal of testosterone stimulation. Pathology. 1984;16(4):406-410.

12. Lockshin RA, Beaulation J. Programmed cell death. Cytochemical evidence for lysosomes during the normal breakdown of the intersegmental muscles. J Ultrastruct Res. 1974;46(1):43-62.

13. Lockshin RA, Beaulaton J. Programmed cell death. Cytochemical appearance of lysosomes when death of the intersegmental muscles is prevented. J Ultrastruct Res. 1974;46(1):63-78.

14. Li W, Yuan X, Nordgren G, et al. Induction of cell death by the lysosomotropic detergent MSDH. FEBS Lett. 2000;470(1):35-39.

15. Boya P, Andreau K, Poncet D, et al. Lysosomal membrane permeabilization induces cell death in a mitochondrion-dependent fashion. J Exp Med. 2003;197(10):1323-1334.

16. Cirman T, Oresić K, Mazovec GD, et al. Selective disruption of lysosomes in HeLa cells triggers apoptosis mediated by cleavage of Bid by multiple papain-like lysosomal cathepsins. J Biol Chem. 2004;279(5):3578-3587.

17. Kågedal K, Zhao M, Svensson I, Brunk UT. Sphingosine-induced apoptosis is dependent on lysosomal proteases. Biochem J. 2001;359 (Pt 2):335-343. 
18. Appelmans F, Wattiaux R, De Duve C. Tissue fractionation studies. 5. The association of acid phosphatase with a special class of cytoplasmic granules in rat liver. Biochem J. 1955;59(3):438-445.

19. de Duve C, Pressman BC, Gianetto R, Wattiaux R, Appelmans F. Tissue fractionation studies. 6. Intracellular distribution patterns of enzymes in rat-liver tissue. Biochem J. 1955;60(4):604-617.

20. Kallunki T, Olsen OD, Jäättelä M. Cancer-associated lysosomal changes: friends or foes? Oncogene. 2013;32(16):1995-2004.

21. Ohkuma S, Moriyama Y, Takano T. Identification and characterization of a proton pump on lysosomes by fluorescein-isothiocyanate-dextran fluorescence. Proc Natl Acad Sci U S A. 1982;79(9):2758-2762.

22. Huotari J, Helenius A. Endosome maturation. EMBO J. 2011;30(17): 3481-3500.

23. Rodríguez A, Webster P, Ortego J, Andrews NW. Lysosomes behave as $\mathrm{Ca} 2+-$ regulated exocytic vesicles in fibroblasts and epithelial cells. J Cell Biol. 1997;137(1):93-104.

24. Guillaumot P, Luquain C, Malek M, et al. Pdro, a protein associated with late endosomes and lysosomes and implicated in cellular cholesterol homeostasis. PLoS One. 2010;5(6):e10977.

25. Salvador N, Aguado C, Horst M, Knecht E. Import of a cytosolic protein into lysosomes by chaperone-mediated autophagy depends on its folding state. J Biol Chem. 2000;275(35):27447-27456.

26. Zhang XD, Qi L, Wu JC, Qin ZH. DRAM1 regulates autophagy flux through lysosomes. PLoS One. 2013;8(5):e63245.

27. Mohamed MM, Sloane BF. Cysteine cathepsins: multifunctional enzymes in cancer. Nat Rev Cancer. 2006;6(10):764-775.

28. Ilan N, Elkin M, Vlodavsky I. Regulation, function and clinical significance of heparanase in cancer metastasis and angiogenesis. Int J Biochem Cell Biol. 2006;38(12):2018-2039.

29. Palermo C, Joyce JA. Cysteine cathepsin proteases as pharmacological targets in cancer. Trends Pharmacol Sci. 2008;29(1):22-28.

30. Vasiljeva O, Reinheckel T, Peters C, Turk D, Turk V, Turk B. Emerging roles of cysteine cathepsins in disease and their potential as drug targets. Curr Pharm Des. 2007;13(4):387-403.

31. Kuester D, Lippert H, Roessner A, Krueger S. The cathepsin family and their role in colorectal cancer. Pathol Res Pract. 2008;204(7): 491-500.

32. Kirkegaard T, Jäättelä M. Lysosomal involvement in cell death and cancer. Biochim Biophys Acta. 2009;1793(4):746-754.

33. Fehrenbacher N, Jäättelä M. Lysosomes as targets for cancer therapy. Cancer Res. 2005;65(8):2993-2995.

34. Groth-Pedersen L, Jäättelä M. Combating apoptosis and multidrug resistant cancers by targeting lysosomes. Cancer Lett. 2013;332(2):265-274.

35. Glunde K, Guggino SE, Solaiyappan M, Pathak AP, Ichikawa Y, Bhujwalla ZM. Extracellular acidification alters lysosomal trafficking in human breast cancer cells. Neoplasia. 2003;5(6):533-545.

36. Ono K, Kim SO, Han J. Susceptibility of lysosomes to rupture is a determinant for plasma membrane disruption in tumor necrosis factor alpha-induced cell death. Mol Cell Biol. 2003;23(2):665-676.

37. Eaton JW, Qian M. Molecular bases of cellular iron toxicity. Free Radic Biol Med. 2002;32(9):833-840.

38. Gyrd-Hansen M, Nylandsted J, Jäättelä M. Heat shock protein 70 promotes cancer cell viability by safeguarding lysosomal integrity. Cell Cycle. 2004;3(12):1484-1485.

39. Mousavi SA, Brech A, Berg T, Kjeken R. Phosphoinositide 3-kinase regulates maturation of lysosomes in rat hepatocytes. Biochem J. 2003; 372(Pt 3):861-869.

40. Madge LA, Li JH, Choi J, Pober JS. Inhibition of phosphatidylinositol 3-kinase sensitizes vascular endothelial cells to cytokine-initiated cathepsindependent apoptosis. J Biol Chem. 2003;278(23):21295-21306.

41. Silverman GA, Bartuski AJ, Cataltepe S, et al. SCCA1 and SCCA2 are proteinase inhibitors that map to the serpin cluster at 18q21.3. Tumour Biol. 1998;19(6):480-487.

42. Suminami Y, Nawata S, Kato H. Biological role of SCC antigen. Tumour Biol. 1998;19(6):488-493.

43. Kirkegaard T, Roth AG, Petersen NH, et al. Hsp70 stabilizes lysosomes and reverts Niemann-Pick disease-associated lysosomal pathology. Nature. 2010;463(7280):549-553.
44. Nylandsted J, Gyrd-Hansen M, Danielewicz A, et al. Heat shock protein 70 promotes cell survival by inhibiting lysosomal membrane permeabilization. J Exp Med. 2004;200(4):425-435.

45. Kuopio T, Kankaanranta A, Jalava P, et al. Cysteine proteinase inhibitor cystatin A in breast cancer. Cancer Res. 1998;58(3):432-436.

46. Liu N, Raja SM, Zazzeroni F, et al. NF-kappaB protects from the lysosomal pathway of cell death. EMBO J. 2003;22(19):5313-5322.

47. Wang B, Sun J, Kitamoto S, et al. Cathepsin S controls angiogenesis and tumor growth via matrix-derived angiogenic factors. J Biol Chem. 2006;281(9):6020-6029.

48. Small DM, Burden RE, Jaworski J, et al. Cathepsin S from both tumor and tumor-associated cells promote cancer growth and neovascularization. Int J Cancer. 2013;133(9):2102-2112.

49. Jedeszko C, Sloane BF. Cysteine cathepsins in human cancer. Biol Chem. 2004;385(11):1017-1027.

50. Joyce JA, Baruch A, Chehade K, et al. Cathepsin cysteine proteases are effectors of invasive growth and angiogenesis during multistage tumorigenesis. Cancer Cell. 2004;5(5):443-453.

51. Xu J, Li D, Ke Z, Liu R, Maubach G, Zhuo L. Cathepsin S is aberrantly overexpressed in human hepatocellular carcinoma. Mol Med Rep. 2009;2(5):713-718.

52. Fernández PL, Farré X, Nadal A, et al. Expression of cathepsins $\mathrm{B}$ and $\mathrm{S}$ in the progression of prostate carcinoma. Int J Cancer. 2001;95(1): $51-55$.

53. Gormley JA, Hegarty SM, O'Grady A, et al. The role of Cathepsin S as a marker of prognosis and predictor of chemotherapy benefit in adjuvant CRC: a pilot study. Br J Cancer. 2011;105(10):1487-1494.

54. Mort JS, Recklies AD, Poole AR. Release of cathepsin B precursors from human and murine tumours. Prog Clin Biol Res. 1985;180:243-245.

55. Mai J, Finley RL, Waisman DM, Sloane BF. Human procathepsin B interacts with the annexin II tetramer on the surface of tumor cells. J Biol Chem. 2000;275(17):12806-12812.

56. Gocheva V, Zeng W, Ke D, et al. Distinct roles for cysteine cathepsin genes in multistage tumorigenesis. Genes Dev. 2006;20(5): 543-556.

57. Sameni M, Elliott E, Ziegler G, Fortgens PH, Dennison C, Sloane BF Cathepsin B and D are Localized at the Surface of Human Breast Cancer Cells. Pathol Oncol Res. 1995;1(1):43-53.

58. Taniguchi S, Nishimura Y, Takahashi T, Baba T, Kato K. Augmented excretion of procathepsin L of a fos-transferred highly metastatic rat cell line. Biochem Biophys Res Commun. 1990;168(2):520-526.

59. Kos J, Lah TT. Cysteine proteinases and their endogenous inhibitors: target proteins for prognosis, diagnosis and therapy in cancer (review). Oncol Rep. 1998;5(6):1349-1361.

60. Koblinski JE, Ahram M, Sloane BF. Unraveling the role of proteases in cancer. Clin Chim Acta. 2000;291(2):113-135.

61. Lakka SS, Gondi CS, Yanamandra N, et al. Inhibition of cathepsin B and MMP-9 gene expression in glioblastoma cell line via RNA interference reduces tumor cell invasion, tumor growth and angiogenesis. Oncogene. 2004;23(27):4681-4689.

62. Linder S, Shoshan MC. Lysosomes and endoplasmic reticulum: targets for improved, selective anticancer therapy. Drug Resist Updat. 2005; 8(4):199-204.

63. Johansson AC, Appelqvist H, Nilsson C, Kågedal K, Roberg K, Ollinger K. Regulation of apoptosis-associated lysosomal membrane permeabilization. Apoptosis. 2010;15(5):527-540.

64. Liu J, Guo Q, Chen B, Yu Y, Lu H, LiYY. Cathepsin B and its interacting proteins, bikunin and TSRC1, correlate with TNF-induced apoptosis of ovarian cancer cells OV-90. FEBS Lett. 2006;580(1):245-250.

65. Bröker LE, Huisman C, Span SW, Rodriguez JA, Kruyt FA, Giaccone G. Cathepsin B mediates caspase-independent cell death induced by microtubule stabilizing agents in non-small cell lung cancer cells. Cancer Res. 2004;64(1):27-30.

66. Emert-Sedlak L, Shangary S, Rabinovitz A, Miranda MB, Delach SM, Johnson DE. Involvement of cathepsin D in chemotherapy-induced cytochrome c release, caspase activation, and cell death. Mol Cancer Ther. 2005;4(5):733-742. 
67. Stoka V, Turk B, Schendel SL, et al. Lysosomal protease pathways to apoptosis. Cleavage of bid, not pro-caspases, is the most likely route. J Biol Chem. 2001;276(5):3149-3157.

68. Reiners JJ, Caruso JA, Mathieu P, Chelladurai B, Yin XM, Kessel D. Release of cytochrome $\mathrm{c}$ and activation of pro-caspase-9 following lysosomal photodamage involves Bid cleavage. Cell Death Differ. 2002;9(9):934-944.

69. Stoka V, Turk V, Turk B. Lysosomal cysteine cathepsins: signaling pathways in apoptosis. Biol Chem. 2007;388(6):555-560.

70. Brunk UT, Svensson I. Oxidative stress, growth factor starvation and Fas activation may all cause apoptosis through lysosomal leak. Redox Rep. 1999;4(1-2):3-11.

71. Yuan XM, Li W, Dalen H, et al. Lysosomal destabilization in $\mathrm{p} 53$-induced apoptosis. Proc Natl Acad Sci U S A. 2002;99(9):6286-6291.

72. Brunk UT, Dalen H, Roberg K, Hellquist HB. Photo-oxidative disruption of lysosomal membranes causes apoptosis of cultured human fibroblasts. Free Radic Biol Med. 1997;23(4):616-626.

73. Chen Z, Sangwan V, Banerjee S, et al. Triptolide sensitizes pancreatic cancer cells to TRAIL-induced activation of the death receptor pathway. Cancer Lett. 2014;348(1-2):156-166.

74. Ogawa Y, Kobayashi T, Nishioka A, et al. Reactive oxygen speciesproducing site in hydrogen peroxide-induced apoptosis of human peripheral T cells: involvement of lysosomal membrane destabilization. Int J Mol Med. 2004;13(3):383-388.

75. Ditaranto-Desimone K, Saito M, Tekirian TL, et al. Neuronal endosomal/lysosomal membrane destabilization activates caspases and induces abnormal accumulation of the lipid secondary messenger ceramide. Brain Res Bull. 2003;59(6):523-531.

76. Boya P, Gonzalez-Polo RA, Poncet D, et al. Mitochondrial membrane permeabilization is a critical step of lysosome-initiated apoptosis induced by hydroxychloroquine. Oncogene. 2003;22(25):3927-3936.

77. Manna SK, Zhang HJ, Yan T, Oberley LW, Aggarwal BB. Overexpression of manganese superoxide dismutase suppresses tumor necrosis factor-induced apoptosis and activation of nuclear transcription factor-kappaB and activated protein-1. J Biol Chem. 1998;273(21): $13245-13254$.

78. Wang JH, Redmond HP, Watson RW, Bouchier-Hayes D. Induction of human endothelial cell apoptosis requires both heat shock and oxidative stress responses. Am J Physiol. 1997;272(5 Pt 1):C1543-C1551.

79. Ferri KF, Kroemer G. Organelle-specific initiation of cell death pathways. Nat Cell Biol. 2001;3(11):E255-E263.

80. Kågedal K, Johansson AC, Johansson U, et al. Lysosomal membrane permeabilization during apoptosis-involvement of Bax? Int $J$ Exp Pathol. 2005;86(5):309-321.

81. Quiogue G, Saggu S, Hung HI, et al. Signaling From Lysosomes Enhances Mitochondria-Mediated Photodynamic Therapy In Cancer Cells. Proc SPIE Int Soc Opt Eng. 2009;7380(73800C):1-8.

82. Česen MH, Pegan K, Spes A, Turk B. Lysosomal pathways to cell death and their therapeutic applications. Exp Cell Res. 2012;318(11): 1245-1251.

83. Turk B, Stoka V, Rozman-Pungercar J, et al. Apoptotic pathways: involvement of lysosomal proteases. Biol Chem. 2002;383(7-8): 1035-1044.

84. Eno CO, Zhao G, Venkatanarayan A, Wang B, Flores ER, Li C. Noxa couples lysosomal membrane permeabilization and apoptosis during oxidative stress. Free Radic Biol Med. 2013;65:26-37.

85. Hornick JR, Vangveravong S, Spitzer D, et al. Lysosomal membrane permeabilization is an early event in Sigma-2 receptor ligand mediated cell death in pancreatic cancer. J Exp Clin Cancer Res. 2012;31:41.

86. Nowak R, Tarasiuk J. Retaining cytotoxic activity of anthrapyridone CO1 against multidrug resistant cells is related to the ability to induce concomitantly apoptosis and lysosomal death of leukaemia HL60/VINC and HL60/DOX cells. J Pharm Pharmacol. 2013;65(6): $855-867$.

87. Li LJ, Zhong LF, Jiang LP, et al. Lysosomal membrane permeabilization contributes to elemene emulsion-induced apoptosis in A549 cells. Free Radic Res. 2011;45(10):1232-1240.
88. Shree T, Olson OC, Elie BT, et al. Macrophages and cathepsin proteases blunt chemotherapeutic response in breast cancer. Genes Dev. 2011;25(23):2465-2479.

89. Wu GS, Saftig P, Peters C, El-Deiry WS. Potential role for cathepsin D in p53-dependent tumor suppression and chemosensitivity. Oncogene. 1998;16(17):2177-2183.

90. Simon S, Roy D, Schindler M. Intracellular $\mathrm{pH}$ and the control of multidrug resistance. Proc Natl Acad Sci U S A. 1994;91(3): 1128-1132.

91. Logan R, Funk RS, Axcell E, Krise JP. Drug-drug interactions involving lysosomes: mechanisms and potential clinical implications. Expert Opin Drug Metab Toxicol. 2012;8(8):943-958.

92. Barbosa CM, Oliveira CR, Nascimento FD, et al. Biphosphinic palladacycle complex mediates lysosomal-membrane permeabilization and cell death in K562 leukaemia cells. Eur J Pharmacol. 2006;542(1-3):37-47.

93. Firestone RA, Pisano JM, Bonney RJ. Lysosomotropic agents. 1. Synthesis and cytotoxic action of lysosomotropic detergents. J Med Chem. 1979;22(9):1130-1133.

94. Burger AM, Jenkins TC, Double JA, Bibby MC. Cellular uptake, cytotoxicity and DNA-binding studies of the novel imidazoacridinone antineoplastic agent C1311. Br J Cancer. 1999;81(2):367-375.

95. Allison AC. Lysosomes in cancer cells. J Clin Pathol Suppl (R Coll Pathol). 1974;7:43-50.

96. Boyer MJ, Tannock IF. Lysosomes, lysosomal enzymes, and cancer. Adv Cancer Res. 1993;60:269-291.

97. Overgaard J. Effect of hyperthermia on malignant cells in vivo. A review and a hypothesis. Cancer. 1977;39(6):2637-2646.

98. Sukhai MA, Prabha S, Hurren R, et al. Lysosomal disruption preferentially targets acute myeloid leukemia cells and progenitors. J Clin Invest. 2013;123(1):315-328.

99. Bidère N, Lorenzo HK, Carmona S, et al. Cathepsin D triggers Bax activation, resulting in selective apoptosis-inducing factor (AIF) relocation in $\mathrm{T}$ lymphocytes entering the early commitment phase to apoptosis. J Biol Chem. 2003;278(33):31401-31411.

100. Joy B, Sivadasan R, Abraham TE, et al. Lysosomal destabilization and cathepsin B contributes for cytochrome c release and caspase activation in embelin-induced apoptosis. Mol Carcinog. 2010;49(4): 324-336.

101. Trincheri NF, Nicotra G, Follo C, Castino R, Isidoro C. Resveratrol induces cell death in colorectal cancer cells by a novel pathway involving lysosomal cathepsin D. Carcinogenesis. 2007;28(5):922-931.

102. Owa C, Messina ME, Halaby R. Triptolide induces lysosomalmediated programmed cell death in MCF-7 breast cancer cells. Int J Womens Health. 2013;5:557-569.

103. Guicciardi ME, Leist M, Gores GJ. Lysosomes in cell death. Oncogene. 2004;23(16):2881-2890.

104. Yu H, Zhou Y, Lind SE, Ding WQ. Clioquinol targets zinc to lysosomes in human cancer cells. Biochem J. 2009;417(1):133-139.

105. Fan C, Wang W, Zhao B, Zhang S, Miao J. Chloroquine inhibits cell growth and induces cell death in A549 lung cancer cells. Bioorg Med Chem. 2006;14(9):3218-3222.

106. Amaravadi RK, Yu D, Lum JJ, et al. Autophagy inhibition enhances therapy-induced apoptosis in a Myc-induced model of lymphoma. $J$ Clin Invest. 2007;117(2):326-336.

107. Sotelo J, Briceño E, López-González MA. Adding chloroquine to conventional treatment for glioblastoma multiforme: a randomized, double-blind, placebo-controlled trial. Ann Intern Med. 2006;144(5): 337-343.

108. Lv X, Liu F, Shang Y, Chen SZ. Honokiol exhibits enhanced antitumor effects with chloroquine by inducing cell death and inhibiting autophagy in human non-small cell lung cancer cells. Oncol Rep. 2015.

109. Grimaldi A, Santini D, Zappavigna S, et al. Antagonistic effects of chloroquine on autophagy occurrence potentiate the anticancer effects of everolimus on renal cancer cells. Cancer Biol Ther. 2015;16(4): $567-579$. 
110. Fukuda T, Oda K, Wada-Hiraike O, et al. The anti-malarial chloroquine suppresses proliferation and overcomes cisplatin resistance of endometrial cancer cells via autophagy inhibition. Gynecol Oncol. 2015;137(3):538-545.

111. De Mei C, Ercolani L, Parodi C, et al. Dual inhibition of REV-ERB $\beta$ and autophagy as a novel pharmacological approach to induce cytotoxicity in cancer cells. Oncogene. 2015;34(20):2597-2608.

112. Di Piazza M, Mader C, Geletneky K, et al. Cytosolic activation of cathepsins mediates parvovirus $\mathrm{H}-1$-induced killing of cisplatin and TRAIL-resistant glioma cells. J Virol. 2007;81(8):4186-4198.

113. Ostenfeld MS, Fehrenbacher N, Høyer-Hansen M, Thomsen C, Farkas T, Jäättelä M. Effective tumor cell death by sigma-2 receptor ligand siramesine involves lysosomal leakage and oxidative stress. Cancer Res. 2005;65(19):8975-8983.

114. Groth-Pedersen L, Ostenfeld MS, Høyer-Hansen M, Nylandsted J, Jäättelä M. Vincristine induces dramatic lysosomal changes and sensitizes cancer cells to lysosome-destabilizing siramesine. Cancer Res. 2007;67(5):2217-2225.

115. Fehrenbacher N, Bastholm L, Kirkegaard-Sørensen T, et al. Sensitization to the lysosomal cell death pathway by oncogene-induced down-regulation of lysosome-associated membrane proteins 1 and 2 . Cancer Res. 2008;68(16):6623-6633.

116. Rammer P, Groth-Pedersen L, Kirkegaard T, et al. BAMLET activates a lysosomal cell death program in cancer cells. Mol Cancer Ther. 2010; 9(1):24-32.

117. Erdal H, Berndtsson M, Castro J, Brunk U, Shoshan MC, Linder S Induction of lysosomal membrane permeabilization by compounds that activate p53-independent apoptosis. Proc Natl Acad Sci U S A. 2005;102(1):192-197.

118. Kang CC, Huang WC, Kouh CW, et al. Chemical principles for the design of a novel fluorescent probe with high cancer-targeting selectivity and sensitivity. Integr Biol (Camb). 2013;5(10):1217-1228.

119. de Duve C. Lysosomes revisited. Eur J Biochem. 1983;137(3): 391-397.

120. Altan N, Chen Y, Schindler M, Simon SM. Defective acidification in human breast tumor cells and implications for chemotherapy. $J \operatorname{Exp}$ Med. 1998;187(10):1583-1598.

121. Kokkonen N, Rivinoja A, Kauppila A, Suokas M, Kellokumpu I, Kellokumpu S. Defective acidification of intracellular organelles results in aberrant secretion of cathepsin D in cancer cells. $J$ Biol Chem. 2004;279(38):39982-39988.
122. Schindler M, Grabski S, Hoff E, Simon SM. Defective $\mathrm{pH}$ regulation of acidic compartments in human breast cancer cells (MCF-7) is normalized in adriamycin-resistant cells (MCF-7adr). Biochemistry. 1996;35(9):2811-2817.

123. Gong Y, Duvvuri M, Krise JP. Separate roles for the Golgi apparatus and lysosomes in the sequestration of drugs in the multidrug-resistant human leukemic cell line HL-60. J Biol Chem. 2003;278(50): 50234-50239.

124. Zhu DM, Uckun FM. Z-Phe-Gly-NHO-Bz, an inhibitor of cysteine cathepsins, induces apoptosis in human cancer cells. Clin Cancer Res. 2000;6(5):2064-2069.

125. Maynadier M, Vezenkov LL, Amblard M, et al. Dipeptide mimic oligomer transporter mediates intracellular delivery of Cathepsin D inhibitors: a potential target for cancer therapy. J Control Release. 2013;171(2):251-257.

126. Katunuma N, Tsuge H, Nukatsuka M, Asao T, Fukushima M. Structurebased design of specific cathepsin inhibitors and their application to protection of bone metastases of cancer cells. Arch Biochem Biophys. 2002;397(2):305-311.

127. Vázquez R, Astorgues-Xerri L, Bekradda M, et al. Fsn0503h antibodymediated blockade of cathepsin $\mathrm{S}$ as a potential therapeutic strategy for the treatment of solid tumors. Biochimie. 2015;108:101-107.

128. Shim JS, Matsui Y, Bhat S, et al. Effect of nitroxoline on angiogenesis and growth of human bladder cancer. J Natl Cancer Inst 2010;102(24):1855-1873.

129. Mirković B, Markelc B, Butinar M, et al. Nitroxoline impairs tumor progression in vitro and in vivo by regulating cathepsin B activity. Oncotarget. 2015.

130. Duong 1T, Wesolowski GA, Leung P, Oballa R, Pickarski M. Efficacy of a cathepsin $\mathrm{K}$ inhibitor in a preclinical model for prevention and treatment of breast cancer bone metastasis. Mol Cancer Ther. 2014;13(12):2898-2909.

131. Chen X, Bi Y, Wang T, et al. Lysosomal targeting with stable and sensitive fluorescent probes (Superior LysoProbes): applications for lysosome labeling and tracking during apoptosis. Sci Rep. 2015;5:9004.

132. Jänicke RU, Sprengart ML, Wati MR, Porter AG. Caspase-3 is required for DNA fragmentation and morphological changes associated with apoptosis. J Biol Chem. 1998;273(16):9357-9360.
Research and Reports in Biology

\section{Publish your work in this journal}

Research and Reports in Biology is an international, peer-reviewed, open access journal publishing original research, reports, editorials, reviews and commentaries on all areas of biology including animal biology, biochemical biology, cell biology, ecological studies, evolutionary biology, molecular biology, plant science and botany. The

\section{Dovepress}

manuscript management system is completely online and includes a very quick and fair peer-review system. Visit http://www.dovepress. $\mathrm{com} /$ testimonials.php to read real quotes from published authors. 